\title{
Internet In Global Settings: A New Look At International Marketing
}

S. Altan Erdem, (E-mail: erdem@cl.uh.edu), University of Houston-Clear Lake

\begin{abstract}
The growing use of e-commerce has opened up a new territory of ongoing communication between consumers and manufacturers around the World. Both parties are now able to target each other regardless of their national boundaries. Accordingly, more and more companies are getting into the international arena and hoping that they can get nicer shares of the potential business volume. Many firms are trying to identify and target specific market segments globally by building a network of Internet sites around the World. While creating a network may just be the beginning, it appears to be a rather successful venture. These businesses are finding out that e-commerce may be a very effective way to reach those markets with similar attributes globally. Considering the continuously increasing speed of technology in the information highway, one can only assume that there will be even more markets attainable in the near future. The question is who will be there first to cover these markets, and more importantly, who will be better prepared to cover them properly.
\end{abstract}

\section{Introduction}

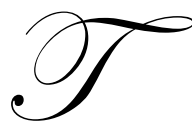

here is no doubt that e-commerce has been the most important business development over the recent years. It has been a common practice for many businesses to gradually switch into options that incorporate the Internet in some form or fashion. The Internet is a new and highly efficient way of accessing, organizing, and sharing information. Among many, Hoffman (2000) described the Internet as "the most important innovation since the development of the printing press" which may "radically transform not just the way individuals go about conducting their business with each other, but also the very essence of what it means to be a human being in society." In the last five years, the number of Internet users has increased more than nineteen fold -over 100 million (Vijayaraman and Bhatia 2002). It is obvious that the Internet use is gaining acceptance by more and more businesses as a viable productivity and marketing tool (Miller and Wood 2002).

With the onset of Internet savvy users, computer technology in the business world has grown more than anyone could have imagined. The growing volume of e-commerce has opened up new areas of communication, cooperation, and coordination among consumers, business units, and trading partners around the World. The Internet has become not only the main medium for marketing, but also the main communications medium for international business. It simply promises to revolutionize the dynamics of international business (Hamill 1997). Firms are now able to target specific market segments worldwide by building a network of websites in different languages throughout the World. Accordingly, it becomes necessary to evaluate traditional marketing approaches and start working on a new framework in global cyberspace at cyber speed.

\section{Impact Of E-Commerce}

As stated by Dutta (1997, p. 61), e-commerce is "the sharing of business information, maintaining business relationships, and conducting business transactions by means of telecommunication networks." Similarly, Reedy, Schullo, and Zimmerman (2000, p. 4) defines e-commerce as "the conducting of business communications and transmissions over networks and through computers, specifically the buying and selling of goods and services, the transfer of funds through digital communications." From a product-based field such as marketing to a service-based area such as healthcare, many functional domains have been receiving their shares of the pie by getting involved in numerous e-commerce practices. While all these areas represent the major areas of inquiry, marketing is still at the very core of this popular trend. 
As suggested by Wenyu and Chou (2002), e-commerce can be classified by the nature of business transactions, including business-to-business (B2B), business-to-consumer (B2C), consumer-to-consumer, consumerto-business, and intraorganizational e-commerce. Among these, B2B and B2C appear to be the two prominent areas. As one would expect, B2B e-commerce includes those cases that both seller and buyers are business corporations while $\mathrm{B} 2 \mathrm{C}$ e-commerce implies that buyers are individual consumers. Although the first wave of the Web was in the B2C domain, the B2B domain is regarded as larger, with e-commerce transactions expected to be in the range of US $\$ 800$ billion by the year 2003 -- five times as much as B2C transactions (Sharma 2002). Similarly, Forrester Research (2000) predicts that B2B revenues over the net will grow to approximately $\$ 2.7$ trillion by 2004 (sevenfold increase over the amount in 2000) as B2C e-commerce will account for \$ 184.5 billion (Webb 2002). While B2C e-commerce is still accounting for a smaller portion of the business, there are some signs that public attention is gradually shifting into this area. As stated by Horrigan and Raini (2002), the Internet has gone from novelty to utility for many, and a growing segment of consumers is spending more time shopping electronically for books, music, and airline tickets. It has been forecasted that by 2010, at least 15 percent of the consumer products will be sold on-line (Rosenbaum 2000).

Many expect that by the end of the century e-commerce will leave no industry untouched and no region immune. Even though e-commerce has already accelerated the pace of change, when it comes to its international applications, some claim that what has been experienced so far is, potentially, only the tip of the iceberg.

Ongoing analytical work at OECD uses a life-cycle model to highlight the phases of e-commerce (see Figure 1 below). Each phase can be measured with different sets of indicators that also correspond to different policy concerns for governments (OECD 2000a; OECD 2000b). E-commerce figures support the argument that we are still in the readiness phase of the cycle.

Figure 1: Source: OECD (2000a)

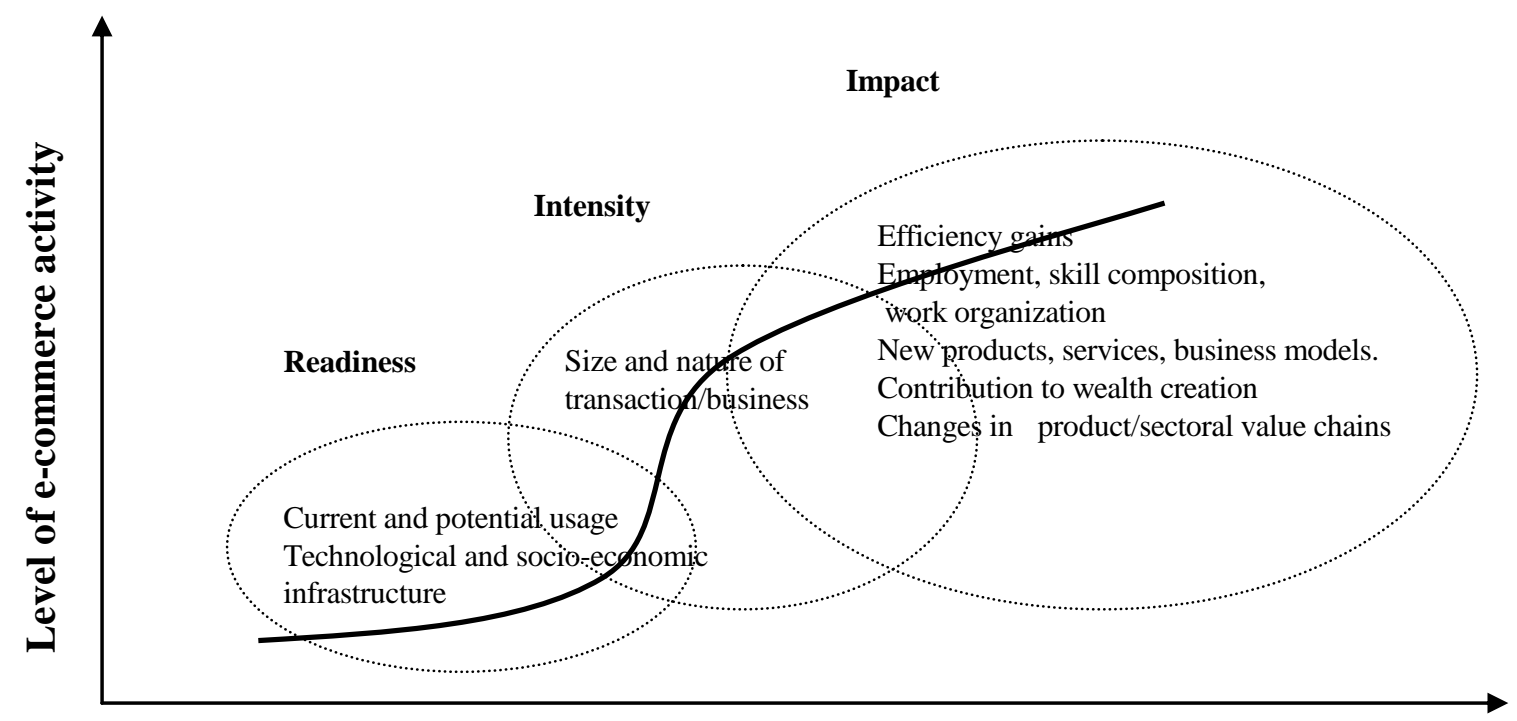

Time

While online buyers are increasing in numbers, the online penetration rate of retail sales is still below 1 percent globally and the ratio of the buyers of the online consumers are around 15 percent (see Figure 2 below). Accordingly, shoppers are still considered to be at the beginning of the movement from physical to cyberspace. 


\section{E-Commerce And International Marketing}

The Internet provides a different environment for international marketing. Materialization of global customers and better links among national marketing communications pave the way for global marketing efforts that result in better service and reduced costs. The Internet has become a very effective communication tool for international marketing. Never before have importing and exporting companies been able to find buyers and sellers in overseas markets with relative ease and low initial expense (Douglas 2001). As suggested by Hamill and Gregory (1997), new customers as well as distributors and a significant amount of information on various issues such as the latest market trends, technology, and R\&D can be identified and generated via the Internet. However, it is also suggested that there are times that the appropriateness of the Internet for international marketing is presumed without a critical examination of the foundations upon which international marketing rests (Samiee 1998). Many assume that e-commerce in emerging markets will evolve along the same lines as it has in the US, North America, and in Western Europe, and that is simply not true (Haley 2002). In reality, the growth of e-commerce is based on a complex network of elements such as information technology at which developed and developing countries are in different development stages (Miller 1997). Accordingly, one should examine the issue in an in-depth fashion to uncover the realities of international markets that may pose practical challenges to marketers before implementing e-commerce in global settings.

Figure 2: B2C E-Commerce Indicators In Selected OECD Countries For 2000 Or Latest Available Year

\begin{tabular}{|c|c|c|c|c|}
\hline & $\begin{array}{l}\text { Value of Transactions } \\
\text { (USD million) }\end{array}$ & $\begin{array}{l}\text { Penetration Rate } \\
\text { of Retail sales }\end{array}$ & $\begin{array}{l}\text { Buyers as a percentage } \\
\text { of Internet users }\end{array}$ & $\begin{array}{c}\text { Internet shoppers as a percentage } \\
\text { of working age population }\end{array}$ \\
\hline USA & 25,845 & $1.01 \%$ & $27 \%$ & $16.0 \%$ \\
\hline Japan & 7,644 & $0.26 \%$ & $20 \%$ & $6.0 \%$ \\
\hline Germany & 1,199 & $0.30 \%$ & $17 \%$ & $5.0 \%$ \\
\hline France & 345 & $0.14 \%$ & $7 \%$ & $2.0 \%$ \\
\hline Italy & 194 & $0.09 \%$ & $7 \%$ & $1.0 \%$ \\
\hline United Kingdom & 1,040 & $0.37 \%$ & $18 \%$ & $5.0 \%$ \\
\hline Canada & 774 & $0.26 \%$ & $12 \%$ & $4.0 \%$ \\
\hline Australia & 380 & $0.36 \%$ & $10 \%$ & $4.0 \%$ \\
\hline Austria & 96 & $0.23 \%$ & $13 \%$ & $2.2 \%$ \\
\hline Belgium & 82 & $0.16 \%$ & $11 \%$ & $3.0 \%$ \\
\hline Denmark & 193 & $0.20 \%$ & $16 \%$ & $9.0 \%$ \\
\hline Finland & 51 & $0.22 \%$ & $10 \%$ & $4.7 \%$ \\
\hline Greece & - & - & $11 \%$ & $0.4 \%$ \\
\hline Ireland & - & - & $13 \%$ & $1.6 \%$ \\
\hline Korea & 1,008 & $1.00 \%$ & $15 \%$ & $7.7 \%$ \\
\hline Netherlands & 182 & $0.34 \%$ & $12 \%$ & $5.0 \%$ \\
\hline Norway & 61 & $0.26 \%$ & $19 \%$ & $11.0 \%$ \\
\hline Portugal & - & - & $10 \%$ & $1.0 \%$ \\
\hline Spain $^{1}$ & 70 & $0.06 \%$ & $7 \%$ & $1.0 \%$ \\
\hline Sweeden & 232 & $0.68 \%$ & $10 \%$ & $4.6 \%$ \\
\hline Switzerland & 127 & $0.29 \%$ & $12 \%$ & $2.7 \%$ \\
\hline
\end{tabular}

\section{Potential Challenges}

There are several consideration areas one has to review before deciding to use the Internet instead of traditional marketing channels in global markets. There is a learning curve that the parties have to master. When companies decide to implement e-commerce in international markets, they quickly realize that there is more to globalization than simply translating their site content. While global website planning includes translation, it goes beyond and deals with issues such as cultural differences, technological constraints, competitive compositions, and regulatory issues. It is common for those companies with no knowledge base and/or limited international e-commerce expertise to outsource some of their tasks to parties called global e-business consultants. These parties are supposed to help companies by delivering quick and cost effective solutions for conducting international business on the Internet. They are charged with assisting those companies in constructing personalized and localized websites for their individual market segments or for worldwide target market segments. Accordingly, they build special websites to assemble customized solutions which 
are designed to be culturally responsive and customer focused. It is believed that these sites are created from actual online behavior and purchase patterns while relating to the cultural details of a particular segment.

Even a fundamental task such as cultural adaptation proves to be a sensitive subject that needs to be handled with care. Language, images, and tones of marketing mixes should be localized to develop culturally sensitive websites that reflect "true global products." Accurate translations with the ultimate attention to details help to incorporate cultural subtleties to attract and retain loyal customers. In order to provide this kind of a service, specialized data collection efforts are made to view online behavior and purchase habits, and to collect demographic and behavioral information within each country. With the help of this information, companies can have marketing websites that are more localized and personalized for individual markets throughout the World (Douglas 2001).

While the concerns about the proper website development are important, they are also more "obvious" than some of the other concerns that are equally important. Many authors (for e.g., Guillen 2002; Javalgi and Ramsey 2001; Samli, Wills, and Herbig 1997; Singh, Jayashankar, and Singh 2001; Walker 2002; Zugelder, Flaherty, and Johnson 2000) have been reviewing some of the other "obvious" concerns such as demographic variations, financial limitations, infrastructure barriers, political intervention, and legal restrictions since the very beginning of the e-commerce craze. While all these are still important, one also has to make sure that the international e-commerce strategy has to cover the challenges associated with global market segmentation and global consumer culture positioning. The following sections outline some of these issues.

\subsection{Global Market Segmentation}

Global market segmentation (GMS) is one of the crucial issues as the global market becomes the business world for today. GMS is the process of identifying specific segments of potential global customers who are likely to exhibit similar buying behavior. These segments can be country groups or individual consumer groups across different countries. Considering the fact that one product can be in different stages of its product life cycle in different countries at any point in time, one can realize the challenges associated with being able to come up with an accurate GMS. While the widespread use of the Internet can ensure that the information on products is quickly distributed across different countries, this distribution would take place in varying portions and fragments due to the differences in the extent of the Internet use in those countries. As one would expect, PC ownership rates differ significantly from one country to another. While some of the countries may have similar ownership figures, access to the Internet by the masses taken for granted (Peterson, Balasubramanian, and Bronnenberg 1997). It is estimated that more than 16 million U.S. homes are expected to have high-speed Internet access by 2004, but this is simply not the case for the rest of the World (Singh, Jayashankar, and Singh 2001). For example, Forrester Research (2000) notes that the Internet diffusion and access appear to be rather low in many European nations (partially due to telephone monopolies in most of these countries).

As suggested by Kumar and Nagpal (2001), one needs to review the conceptual and mechanical aspects of the global arena to allow GMS to be effective. Segments must be continually revaluated to ensure that segment memberships assigned are properly tuned into the attitudes and technologies within that segment. Similarly, one has to make sure that the countries in question are comparable with one another. By this way, it might be possible to break down the world market to ensure proper product marketing mixes for each different product within each segment. Once this is done, companies can try to customize their marketing mixes to compliment each segment. It is important that these segments are categorized and divided by various measurable developments. While some might use certain trends as they relate to demographic and sociocultural factors which have being used by marketers over the years for segmentation purposes, today's fast-paced, highly technical world requires additional dimensions such consumers' purchase patterns and response variances. Purchase patterns can help to determine the sequence of countries in which products should be introduced. One may need to examine whether a certain segment should be a lead or lag segment. Similarly, one may need to investigate how fast the information is transferred from one segment to another. Finally, one may decide to employ special discount strategies in certain segments due to unique responses to price changes in those segments. 
Some of the challenges that face global marketers are associated with insufficient research, overstandardization of segments, and poor implementation of GMS. How companies decide to form a global strategy will effectively decide the degree in which sales increase in the global marketplace. As stated by Kumar and Nagpal (2001), the successful global marketers are the ones who can achieve a balance between the local and the global concerns. One of the major requirements for the global marketers in being able to take advantage of similar attributes like economies of scale and sociocultural issues in promoting their products/brands is the proper development and employment of GMS.

\subsection{Global Consumer Culture Positioning}

The growing use of the Internet is changing not only many rituals in the marketplace but also the consumer culture that marketers have been investigating over the recent decades. One new set of widely understood ideas and symbols is called global consumer culture positioning (GCCP). While GCCP is a new tool in the global marketing segmentation, it is held in high regard by corporate strategists. The objective is to use GCCP as a positioning device in understanding how a product can become a part of the multinational marketplace. Associating people through similar or parallel attributes should help in identifying global segments. Once companies master these segments, they can actually work on creating a global image. As Alden and Betra (1999) suggest, brands that have global images are more likely to gain unique creditability and authority within targeted segments. This means increasing sales for those companies.

There are numerous verbal, thematic, and visual issues that one can investigate in developing brand associations in GCCP for companies to use across different global segments. One major advantage that the U.S. companies have in this area is the fact that English is being viewed as the primary language in international business. Even though by 2005 about 70 percent of the Internet users are expected to speak a language besides English (Heckman and Schmidt 2000), at the moment in many cultures English is still perceived as the main language to reach global markets that possess a social mobility and a cosmopolitan way of life. While U.S. companies enjoy this luxury in terms of language, they are still faced with certain challenges in terms of aesthetic or visual displays of brands. These companies need to review the potential effects of their company logos and other visual information on their global positions. Alden and Betra (1999) add that the actual themes through which the companies are identified are equally important and one has to make sure that these companies are not limiting themselves in their local and/or foreign markets by the themes they use.

\section{Conclusion}

The growing use of e-commerce has opened up a new territory of ongoing communication between consumers and manufacturers around the World. Both parties are now able to target each other regardless of their national boundaries. Accordingly, more and more companies are getting into the international arena and hoping that they can get nicer shares of the potential business volume. Many firms are trying to identify and target specific market segments globally by building a network of Internet sites around the World. While creating a network may just be the beginning, it appears to be a rather successful venture. These businesses are finding out that e-commerce may be a very effective way to reach those markets with similar attributes globally. Considering the continuously increasing speed of technology in the information highway, one can only assume that there will be even more markets attainable in the near future. The question is who will be there first to cover these markets, and more importantly, who will be better prepared to cover them properly.

\section{References}

1. Achrol, R. and P. Kotler (1999), "Marketing in the Network Economy", Journal of Marketing, 63, 146-163.

2. Alden, D. and R. Betra (1999), "Brand Positioning Through Advertising in Asia, North America, and Europe: The Role of Global Consumer Culture", Journal of Marketing, 63, 75-87.

3. Douglas, S. (2001), "Exploring New Worlds: The Challenge of Global Marketing”, Journal of Marketing, 65, 103-107.

4. Dutta, A. (1997), "The Physical Infrastructure for Electronic Commerce in Developing Nations: Historical Trends and the Impact of Privatization", International Journal of Electronic Commerce, 2, 66-83. 
5. Forrester Research, Inc. (2000), “Global E-Commerce Approaches Hypergrowth”, [online] April 18.

6. Guillen, M. F. (2002), "What is the Best Global Strategy for the Internet?” Business Horizons, 45, 39-46.

7. Haley, G. T. (2001), E-Commerce in China Changing Business as We Know It", Industrial Marketing Management, 31, 119-124.

8. Hamill, J. (1997), "The Internet and International Marketing”, International Marketing Review, 14, $300-323$.

9. Hamill, J. and K. Gregory (1997), "Internet Marketing in the Internationalisation of UK SMEs", Journal of Marketing Management, 13, 9-28.

10. Heckman, J. and K. V. Schmidt (2000), "International in Internet Closes US Lead”, Marketing News, Feb. 14, 7-8.

11. Hoffman, D. (2000), "The Revolution will not be Televised: Introduction to the Special Issue on Marketing Science and Internet", Marketing Science, 19, 1-3.

12. Hoffman, D. and T. Novak (1996), "Marketing in Hypermedia Computer-Mediated Environments", Journal of Marketing, 60, 50-68.

13. Horrigan, J. B., and L. Raini (2002), "Getting Serious Online", Pew Internet and American Life Project, March 3, (www.pewinternet.org/).

14. Javalgi, R. and R. Ramsey (2001), "Strategic Issues of E-Commerce as an Alternative Global Distribution System", International Marketing Review, 18, 376-391.

15. Kumar, V. and A. Nagpal (2001), "Segmenting Global Markets: Look Before You Leap", Journal of Marketing Research, 13, 8-13.

16. Miller, G. K. (1997), "Infrastructure Development Speeding the Process", Asiamoney, 8, 62-64.

17. Miller, R. A., and J. T. Wood (2002), "Perceptions about Internet Commerce: A Student Survey", Journal of Internet Commerce, 1, 37-48.

18. OECD (2000a), "Defining and Measuring Electronic Commerce: A Background Paper", DSTI/CCP/IIS, April.

19. OECD (2000b), "Information Technology Outlook", Paris.

20. Peterson, R. A., S. Balasubramanian, and B. J. Bronnenberg (1997), "Exploring the Implications of the Internet for Consumer Marketing”, Journal of the Academy of Marketing Science, 25, 329-346.

21. Reedy, J., S. Schullo, and K. Zimmerman (2000). Electronic Marketing: Integrating Electronic Resources into the Marketing Process, Orlando (FL): Harcourt, Inc.

22. Rosenbaum, (2000), "The Information Environment of Electronic Commerce: Information Imperatives for the Firm", Journal of Information Science, 26, 161-171.

23. Samiee, S. (1998), "Exporting and the Internet: A Conceptual Perspective", International Marketing Review, $15,413-426$.

24. Samli, A. C., J. R. Wills, Jr., and P. Herbig (1997), “The Information Superhighway Goes International: Implications for Industrial Sales Transactions", Industrial Marketing Management, 26, 51-58.

25. Sharma, A. (2002), "Trends in Internet-Based B2B Marketing”, Industrial Marketing Management, 31, 77-84.

26. Singh, T., J. V. Jayashankar, and J. Singh (2001), "E-Commerce in the U.S. and Europe - Is Europe Ready to Compete?" Business Horizons, 44, 6-17.

27. Vijayaraman, B. S., and G. Bhatia (2002), "A Framework for Determining Success Factors of an ECommerce Initiative", Journal of Internet Commerce, 1, 63-75.

28. Walker, L. J. H. (2002), "If You Build It, Will They Come? Barriers to International E-Marketing", Journal of Marketing Theory and Practice, 10, 12-21.

29. Webb, K. L. (2002), "Managing Channels of Distribution in the Age of Electronic Commerce", Industrial Marketing Management, 31, 95-102.

30. Wenyu, D. and D. C. Chou (2001), "A Structural Analysis of Business-to-Business Digital Markets", Industrial Marketing Management, 31, 165-176.

31. Zugelder, M. T., T. B. Flaherty, and J. P. Johnson (2000), "Legal Issues Associated With International Internet Marketing", International Marketing Review, 17, 253-271. 